\title{
Effect of dsRNA on Mesangial Cell Synthesis of Plasminogen Activator Inhibitor Type 1 and Tissue Plasminogen Activator
}

\author{
Markus Wörnle $^{\mathrm{a}}$ Maximilian Roeder ${ }^{\mathrm{a}}$ Matthias Sauter ${ }^{\mathrm{a}}$ Monika Merkle $^{\mathrm{b}}$ \\ Andrea Ribeiro $^{\mathrm{a}}$ \\ ${ }^{a}$ Medical Policlinic, Ludwig Maximilians University, Munich, and b ${ }^{\mathrm{b}}$ Department of Nephrology, Klinikum Traunstein, \\ Traunstein, Germany
}

\section{Key Words}

Plasminogen activator inhibitor type $1 \cdot$ Poly(l:C) RNA •

Polyriboinosinic:polyribocytidylic acid •

Retinoic acid-inducible gene I - Toll-like receptor 3 •

Tissue plasminogen activator

\begin{abstract}
Background/Aims: Viral infections are a major problem worldwide and many of them are complicated by virally induced glomerulonephritides. Progression of kidney disease to renal failure is mainly attributed to the development of renal fibrosis characterized by the accumulation of extracellular matrix components in the mesangial cell compartment and the glomerular basement membrane. Plasminogen activator inhibitor type 1 (PAI-1) and tissue plasminogen activator ( $\mathrm{t}-\mathrm{PA}$ ) are major regulators of plasmin generation and play an important role in generation and degradation of glomerular extracellular matrix components. Viral receptors expressed by mesangial cells (MC) are known to be key mediators in immune-mediated glomerulonephritis. We investigated the effect of stimulation of the viral receptors tolllike receptor 3 (TLR3) and retinoic acid-inducible gene I (RIG-I) on the expression of PAI-1 and t-PA. Methods: Expression of PAI- 1 and t-PA in immortalized human MC stimulated with polyriboinosinic:polyribocytidylic acid [poly(l:C)] RNA and cytokines were analyzed by real-time RT-PCR and ELISA. Results: Incubation of MC with poly(I:C) RNA to activate the
\end{abstract}

\section{KARGER}

Fax +41613061234 E-Mail karger@karger.ch www.karger.com (c) 2009 S. Karger AG, Basel

$1660-2129 / 09 / 1132-0057 \$ 26.00 / 0$

Accessible online at:

www.karger.com/nee viral receptors TLR3 and RIG-I upregulates the expression of PAI-1 and t-PA. Knockdown of viral receptors with specific siRNA abolishes the induction of PAI-1 and t-PA. Conclusion: For the first time a link between the activation of viral receptors on MC and potentially causative agents in the development of glomerulosclerosis and tubulointerstitial fibrosis is shown. The progression of inflammatory processes to glomerulosclerosis can be postulated to be directly enhanced by viral infection.

Copyright $\odot 2009$ S. Karger AG, Basel

\section{Introduction}

Tissue plasminogen activator (t-PA) and plasminogen activator inhibitor type 1 (PAI-1) are the major regulators of plasmin generation. t-PA plays a pivotal role in the fibrinolytic system by converting the proenzyme plasminogen into the active enzyme plasmin. Plasmin is a potent broad-spectrum protease that cleaves fibrin and is able to degrade several components of the extracellular matrix (ECM) by activating procollagenases and matrix metalloproteinases (MMPs) [1]. PAI-1 is an important inhibitor of plasminogen activators [2].

In proliferative or crescentic forms of glomerulonephritis, the extent of fibrin deposits correlates with the severity of glomerular lesions [3, 4]. Progression to renal failure is mainly attributed to the development of glo-

Dr. Markus Wörnle

Medizinische Poliklinik - Klinikum der LMU

Pettenkoferstrasse 8a, DE-80336 München (Germany)

Tel. +49 895160 3511, Fax +49895160 4924

E-Mail Markus.Woernle@med.uni-muenchen.de 
merular and interstitial fibrosis [5] with glomerulosclerosis being characterized by an accumulation of ECM $[6$, 7]. As plasmin activates MMPs and thereby degrades ECM components, a reduced glomerular plasmin production caused by decreased t-PA or increased PAI-1 activity was postulated to be relevant for the progression of human glomerulonephritis and various forms of experimental glomerulonephritis in several studies [8-11].

With viral infections gaining in global importance, the number of virally induced glomerulonephritides increases steadily. During the course of hepatitis $\mathrm{C}$ virus (HCV) infection, immune complexes and viral RNA are found in the mesangium and often cause clinically relevant glomerulonephritis [12, 13]. HIV-associated nephropathy affects up to $10 \%$ of HIV-seropositive individuals and is mainly characterized by focal segmental glomerulosclerosis [14]. IgA nephropathy as the most common glomerulonephritis is often preceded by viral upper respiratory tract infections and is characterized by mesangial cell proliferation and mesangial matrix expansion [15].

Toll-like receptors (TLRs) are an essential part of the innate immune system and are expressed on immune cells as well as on a number of non-immune cells. TLRs recognize conserved pathogen-associated molecular patterns associated with microbial pathogens and induce an immune response [16]. Eleven members of the TLR family (TLR1-11) have so far been identified in mice and ten in humans, each recognizing a distinct component of an infectious agent [17]. TLR3 recognizes dsRNA of viral origin as exemplified by polyriboinosinic:polyribocytidylic acid [poly(I:C)] RNA, a synthetic analogue of viral dsRNA $[18,19]$. TLR3 expression is not restricted to leukocytes but also occurs in non-immune organs, including lung and bowel [20]. Beside TLR3, the helicase retinoic acid-inducible gene I (RIG-I) may also act as a sensor of viral infections through recognition of viral dsRNA and may upregulate type I interferons [21].

In adult healthy kidneys, TLR3 can be found on mesangial cells (MC), vascular smooth muscle cells and collecting duct epithelium by immunohistochemistry. Immortalized human MC have low TLR3 mRNA levels with a predominant intracellular protein localization. We have shown that TLR 3 expression in MC is increased by tumor necrosis factor- $\alpha$ (TNF- $\alpha$ ), interleukin (IL)-1 $\beta$, interferon- $\gamma($ IFN- $\gamma$ ) and the TLR3 ligand poly(I:C) RNA, which also increases mRNA and protein synthesis of IL-6, IL$1 \beta$, M-CSF, IL-8/CXCL8, RANTES/CCL5, MCP-1/CCL2 and ICAM-I in MC and has antiproliferative and proapoptotic effects. We therefore postulated that TLR3 may be important for the clearance of any viral RNA reaching the glomerular mesangium. In highly replicative viral infections such as active hepatitis C, free viral RNA as well as viral RNA bound to immune complexes could trigger glomerular inflammatory processes and result in glomerulonephritis by activating TLR3 [13, 22]. In support of this hypothesis, we have previously shown the role of TLR3 expressed on human MC in hepatitis C-associated glomerulonephritis [23]. We found increased mRNA levels for TLR3 and for proinflammatory cy tokines and chemokines in microdissected glomeruli from biopsies of hepatitis C-associated but not idiopathic membranoproliferative glomerulonephritis. We also have previously shown that activation of viral receptors leads to an upregulation of mesangial expression of MMP9 without affecting synthesis of MMP2 and the tissue inhibitor of MMPs TIMP-1 [24].

We now investigated the effect of viral RNA on mesangial synthesis of PAI-1 and t-PA as important regulators of glomerular fibrin turnover and potentially causative agents in development of glomerular sclerosis and tubulointerstitial fibrosis. Stimulation of immortalized human MC with poly(I:C) RNA mimicking viral RNA was done and expression of PAI-1 and t-PA analyzed. Specific mediation of the effects by viral receptors was shown by knockdown experiments.

\section{Methods}

Cell Culture of Human MC

Immortalized human $\mathrm{MC}$ were grown as described previously [25]. MC were incubated with TNF- $\alpha$ (25 ng/ml), IL-1 $\beta$ (10 ng/ $\mathrm{ml})$ and IFN- $\gamma(20 \mathrm{ng} / \mathrm{ml})$ or culture medium alone (control) for $24 \mathrm{~h}$, washed with PBS, incubated in culture medium (containing $10 \%$ fetal calf serum) for $6 \mathrm{~h}$ and washed again with PBS. Subsequently, MC were incubated with culture medium containing poly(I:C) RNA in different concentrations as indicated below or culture medium alone (control). For expression analysis, extraction of total RNA was performed using an RNeasy Mini Kit (Qiagen, Germany) with DNase digestion.

Reverse Transcriptase-Polymerase Chain Reaction (RT-PCR) Analysis

RT-PCR analysis was done as described [26]. For RT-PCR, $2 \mu \mathrm{g}$ of isolated total RNA underwent random primed reverse transcription using a modified Moloney murine leukemia virus reverse transcriptase (Superscript; Life Technologies, Germany). In parallel, $2-\mu \mathrm{g}$ aliquots were processed without reverse transcription to control for contaminating genomic DNA. Real-time RTPCR was performed on a TaqMan ABI 7700 sequence detection system (PE Applied Biosystems, Germany). GAPDH was used as reference housekeeping gene. All water controls were negative for target and housekeeper. RT-PCR quantitation was done by the 


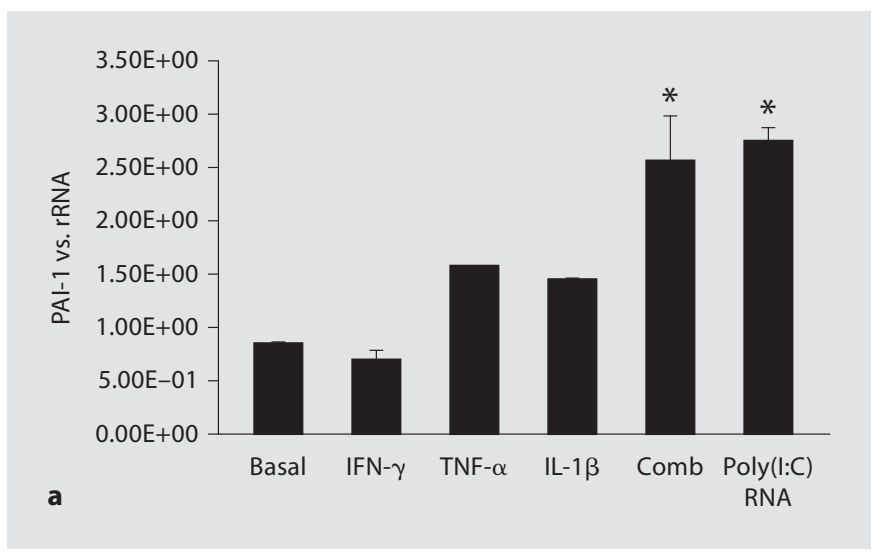

Fig. 1. Expression of PAI-1 and t-PA by human MC. Human MC were cultured under standard conditions (Basal) or after stimulation with proinflammatory cytokines TNF- $\alpha$, IL-1 $\beta$ and IFN- $\gamma$ alone or in combination (Comb) as well as the analogue of viral RNA poly(I:C) RNA ( $5 \mu \mathrm{g} / \mathrm{ml})$ for $24 \mathrm{~h}$ before RNA extraction. Real-time RT-PCR was performed using primers specific for human PAI-1 and t-PA as indicated in Methods. a Basal expression of PAI was not affected by stimulation with IFN- $\gamma$. TNF- $\alpha$ and

Pfaffl method. Sequences with the following GenBank accession numbers were used to design the predeveloped TaqMan assay reagents (PDAR) primers and probe, purchased from Applied Biosystems: NM003265/U88879 (human TLR3), NM014314 (human RIG-I), NM000602.1, M16006.1, M14083.1, X12701.1 (human PAI-1), NM033011.2, NM000930.3, M15518.1, D01096.1 (human t-PA) and M33197 (human GAPDH).

Knockdown of Gene Expression with Short Interfering RNA (siRNA)

Predesigned siRNA specific for TLR3 and RIG-I were purchased from Ambion (Japan). Transfection of siRNA into the cells was performed as described before [27]. Scrambled siRNA was used as the non-specific negative control of siRNA (Ambion).

\section{Statistical Analysis}

Values are provided as mean \pm SEM. Statistical analysis was performed by ANOVA analysis. Significant differences are indicated for $\mathrm{p}$ values $<0.05\left(^{*}\right)$ or $0.01\left({ }^{* *}\right)$, respectively.

\section{Results}

mRNA Expression of PAI-1 and t-PA by Human MC

$\mathrm{MC}$ were cultured under standard conditions or stimulated with the cytokines TNF- $\alpha$, IL- $1 \beta$ and IFN- $\gamma$ alone or in combination or with poly(I:C) RNA (5 $\mu \mathrm{g} / \mathrm{ml})$, a synthetic analogue of viral RNA, for $24 \mathrm{~h}$. Expression of PAI1 and t-PA was analyzed by real-time RT-PCR. PAI-1 expression was not affected by IFN- $\gamma$ stimulation and not

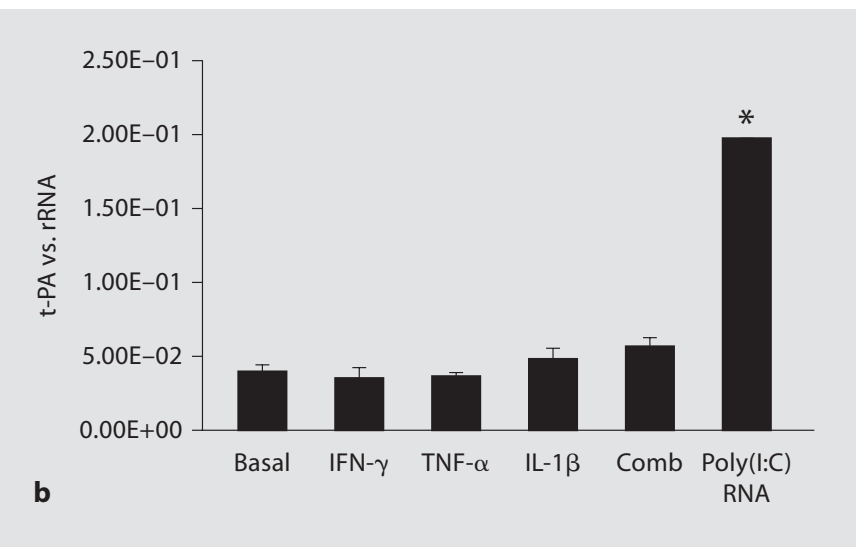

IL-1 $\beta$ stimulation led to an increase of PAI-1 synthesis. The cytokine combination (TNF- $\alpha$, IL- $1 \beta$, IFN- $\gamma$ ) and poly(I:C) RNA clearly increased PAI-1 expression. $\mathbf{b}$ Basal expression of t-PA was not affected by any of the cytokines individually or in combination. Poly(I:C) RNA increased t-PA synthesis. Results are mean \pm SEM of three independently performed experiments and rRNA served as the reference gene. Significant differences are indicated for $\mathrm{p}$ values $<0.05\left(^{*}\right)$.

significantly increased by TNF- $\alpha$ or IL- $1 \beta$ alone. PAI- 1 expression was increased significantly and to a comparable extent by combined stimulation with TNF- $\alpha$, IL-1 $\beta$ and IFN- $\gamma$ and by poly(I:C) RNA. Basal expression of t-PA was not affected by any of the proinflammatory cytokines individually or in combination. In contrast, poly(I:C) RNA increased mesangial t-PA expression (fig. 1).

\section{Effect of Incubation with Poly(I:C) RNA on Expression and Synthesis of PAI-1 and $t-P A$}

MC exhibit a basal expression of viral receptors TLR3 and RIG-I which is increased under inflammatory conditions comparable to those occurring in immune-mediated glomerular disease [23]. mRNA expression of TLR3 and RIG-I was analyzed by RT-PCR under basal conditions and after a 24-hour stimulation with a combination of proinflammatory cytokines (TNF- $\alpha$, IL-1 $\beta$, IFN- $\gamma$ ). The low basal expression of TLR3 and RIG-I was increased when cells were stimulated with the proinflammatory cytokines (fig. 2a, b). To test the relevance of activation of viral receptors TLR3 and RIG-I for PAI-1 and t-PA synthesis, MC were stimulated with poly(I:C) RNA mimicking viral RNA. MC were incubated with (Comb) or without (Basal) a combination of cytokines for $24 \mathrm{~h}$, washed with PBS, incubated in culture medium for $6 \mathrm{~h}$ and washed again with PBS. Subsequently, MC were incubated with culture medium alone (control) or culture 
medium containing poly(I:C) RNA in different concentrations $(0.5,5,10 \mu \mathrm{g} / \mathrm{ml})$ for $24 \mathrm{~h}$. PAI-1 (fig. $2 \mathrm{c}, \mathrm{d})$ and t-PA (fig. 2e, f) expression and synthesis were analyzed by RT-PCR and ELISA. A dose-dependent increase in PAI-1 mRNA was observed after stimulation of the cells with poly(I:C) RNA both under basal conditions and after cytokine pretreatment. The cytokine pretreatment had no additive effect on the induction of PAI-1 expression. Protein analysis by ELISA showed a dose-dependent increase in PAI-1 release with poly(I:C) RNA stimulation; protein synthesis was enhanced by pretreatment with cytokines. Exposure of MC to poly(I:C) RNA at a concentration of 0.5 or $5 \mu \mathrm{g} / \mathrm{ml}$ increased significantly t-PA mRNA levels in a dose-dependent manner, an effect which was further

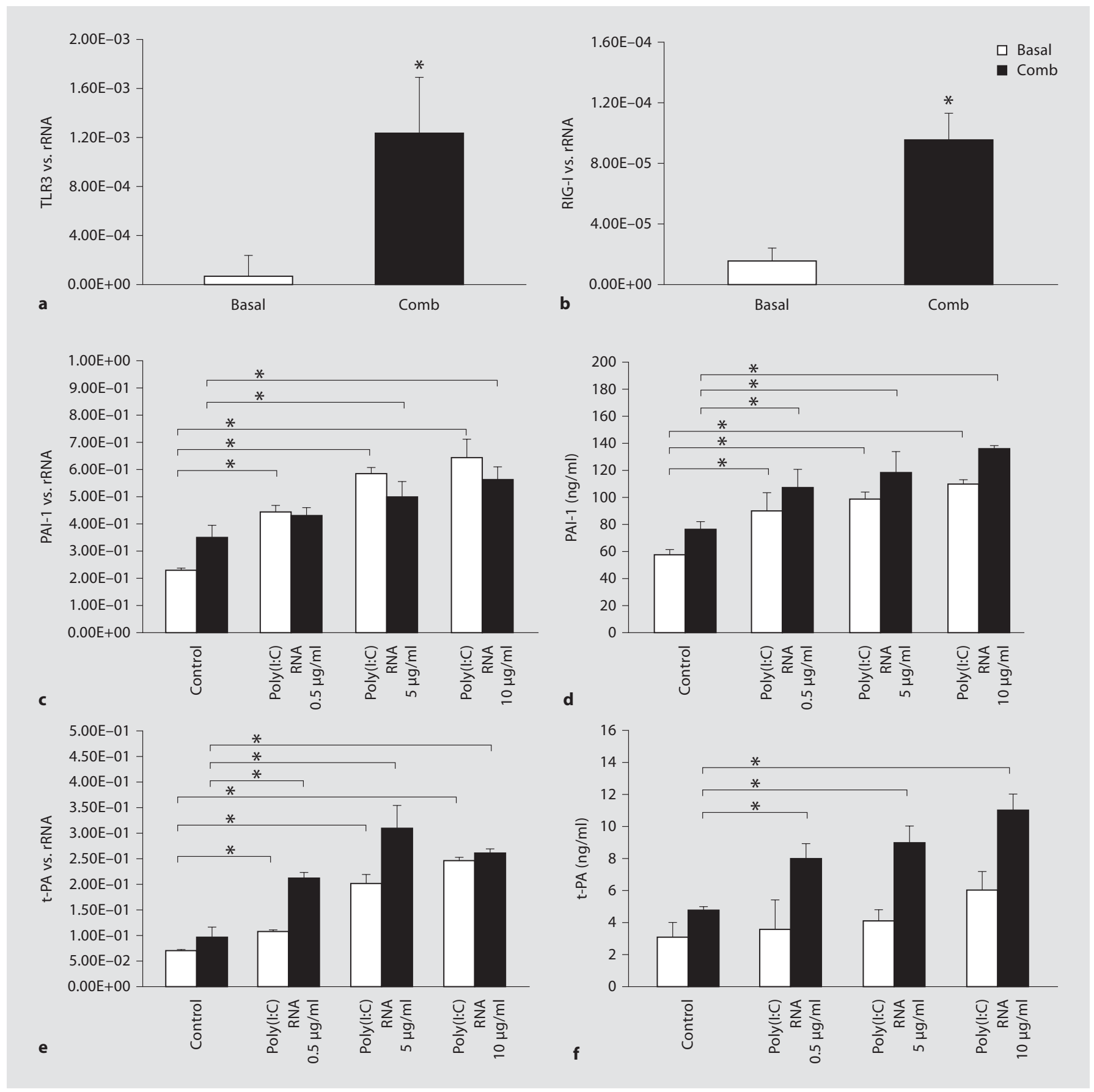


enhanced with pretreatment of MC with the cytokine combination. A significant increase in t-PA protein was observed only when cells were pretreated with the combination of proinflammatory cytokines and additionally stimulated with poly(I:C) RNA.

\section{Time Course of PAI-1 and t-PA Expression and}

\section{Synthesis after Stimulation with Poly(I:C) RNA}

Expression and synthesis of PAI-1 and t-PA were analyzed by real-time RT-PCR and ELISA after incubation of MC with poly(I:C) RNA $(5 \mu \mathrm{g} / \mathrm{ml})$ for up to $24 \mathrm{~h}$ with and without pretreatment of cells with the cytokine combination specified above. Stimulation both with the cytokines and with poly(I:C) RNA led to a comparable increase in PAI-1 mRNA, which started to be significant compared to baseline after $6 \mathrm{~h}$. The increase in PAI-1 mRNA after poly(I:C) RNA stimulation was enhanced significantly when $\mathrm{MC}$ were pretreated with the cytokine combination. Under these conditions, PAI-1 expression peaked at 3 and 6 h. At 12 and 24 h, PAI- 1 expression was found to be increased compared to MC cultured under basal conditions, but no difference was found to cells stimulated with cytokines alone (fig. 3a). Analysis by ELISA showed a significant increase in PAI-1 synthesis only in cytokine pretreated cells after poly(I:C) stimulation for 12 and

Fig. 2. Effect of incubation with poly(I:C) RNA on production of PAI-1 and t-PA. MC exhibit a low expression of TLR3 (a) and RIGI (b) under basal conditions (Basal) which could be increased by a 24-hour stimulation with a combination of the proinflammatory cytokines TNF- $\alpha$, IL- $1 \beta$ and IFN- $\gamma$ (Comb). To test the effect of activation of viral receptors $\mathrm{MC}$ were preincubated with (Comb) or without (Basal) a combination of proinflammatory cytokines (TNF- $\alpha$, IL-1 $\beta$, IFN- $\gamma$ ) for $24 \mathrm{~h}$, washed with PBS, incubated in culture medium for $6 \mathrm{~h}$, washed again with PBS and incubated with or without (control) poly(I:C) RNA in different concentrations $(0.5,5,10 \mu \mathrm{g} / \mathrm{ml})$ for $24 \mathrm{~h}$ before RNA extraction. Expression for PAI-1 and t-PA were analyzed by real-time RT-PCR (c,e) and ELISA (d, f). Expression of PAI-1 (c, d) was increased by poly(I:C) RNA in a dose-dependent manner in a range from 0.5 to $10 \mu \mathrm{g} / \mathrm{ml}$ poly(I:C) RNA under basal conditions and after additional cytokine pretreatment. Stimulation with poly(I:C) RNA $(\mathbf{e}, \mathbf{f})$ increased t-PA expression of $\mathrm{MC}$ in a concentration-dependent manner in a range from 0.5 to $10 \mu \mathrm{g} / \mathrm{ml}$ poly(I:C) RNA, an effect enhanced by pretreatment with the cytokine combination, when mRNA expression was analyzed by RT-PCR. When t-PA release was analyzed by ELISA, the dose-dependent increase was significant, when cells were pretreated with the combination of proinflammatory cytokines. Results are mean \pm SEM of three independently performed experiments and rRNA served as the reference gene. Significant differences are indicated for $\mathrm{p}$ values $<0.05$ $(*)$.

PAI-1 and t-PA in Glomerulonephritis
$24 \mathrm{~h}$. The effect of poly(I:C) RNA stimulation alone on PAI-1 synthesis was comparable to treatment with the cytokine combination; the induced increase in PAI-1 synthesis was significant compared to basal conditions only at $24 \mathrm{~h}$ (fig. 3b). t-PA mRNA expression was increased in a time-dependent manner by poly(I:C) RNA stimulation and further enhanced after additional cytokine pretreatment. When MC were prestimulated with proinflammatory cytokines, the increase in t-PA mRNA was significant at 6,12 and $24 \mathrm{~h}$, the maximal peak was found after $24 \mathrm{~h}$. Again there was no difference between the significant increases in t-PA mRNA induced by cytokines and with poly(I:C) RNA alone at 12 and $24 \mathrm{~h}$ (fig. $3 \mathrm{c}$ ). No increase in t-PA synthesis was observed by ELISA when cells were stimulated with poly(I:C) RNA for 3 and $6 \mathrm{~h}$, both with and without cytokine pretreatment. After 12 and $24 \mathrm{~h}$ of poly(I:C) RNA stimulation, t-PA release increased significantly under basal conditions, an effect which was further enhanced when cells were pretreated with the cytokine combination. The maximum increase was observed at $24 \mathrm{~h}$ (fig. 3d).

\section{Effect of Transfection with siRNA Specific for TLR3}

and RIG-I on Poly(I:C) RNA-Induced PAI-1 and t-PA

Expression and Synthesis

MC constitutively express mRNA for TLR3 and RIG-I. Transfection of MC with siRNA specific for these viral receptors for $24 \mathrm{~h}$ caused remarkable downregulation of these genes under basal conditions. Expression of TLR3 after transfection with siRNA specific for TLR3 was 10\% of basal TLR3 expression, expression of RIG-I after transfection with siRNA specific for RIG-I was $17 \%$ of basal RIG-I expression (fig. 4a). MC were stimulated with poly(I:C) RNA $(5 \mu \mathrm{g} / \mathrm{ml})$ for $24 \mathrm{~h}$. To avoid influence of cytokines on expression of PAI-1 and t-PA, cells were not pretreated with the cytokine combination mentioned above. Poly(I:C) RNA significantly increased expression of PAI-1 (fig. 4b) and t-PA (fig. 4c). siRNA specific for TLR3 reduced significantly poly(I:C) RNA-induced expression of PAI-1 and t-PA. siRNA specific for RIG-I had no effect on poly(I:C) RNA-induced expression of PAI-1 and t-PA.

\section{Discussion}

In this study we analyzed the expression and synthesis of PAI- 1 and t-PA in human MC in response to viral RNA exemplified by the synthetic analogue of viral RNA poly(I:C) RNA.

Nephron Exp Nephrol 2009;113:e57-e65 

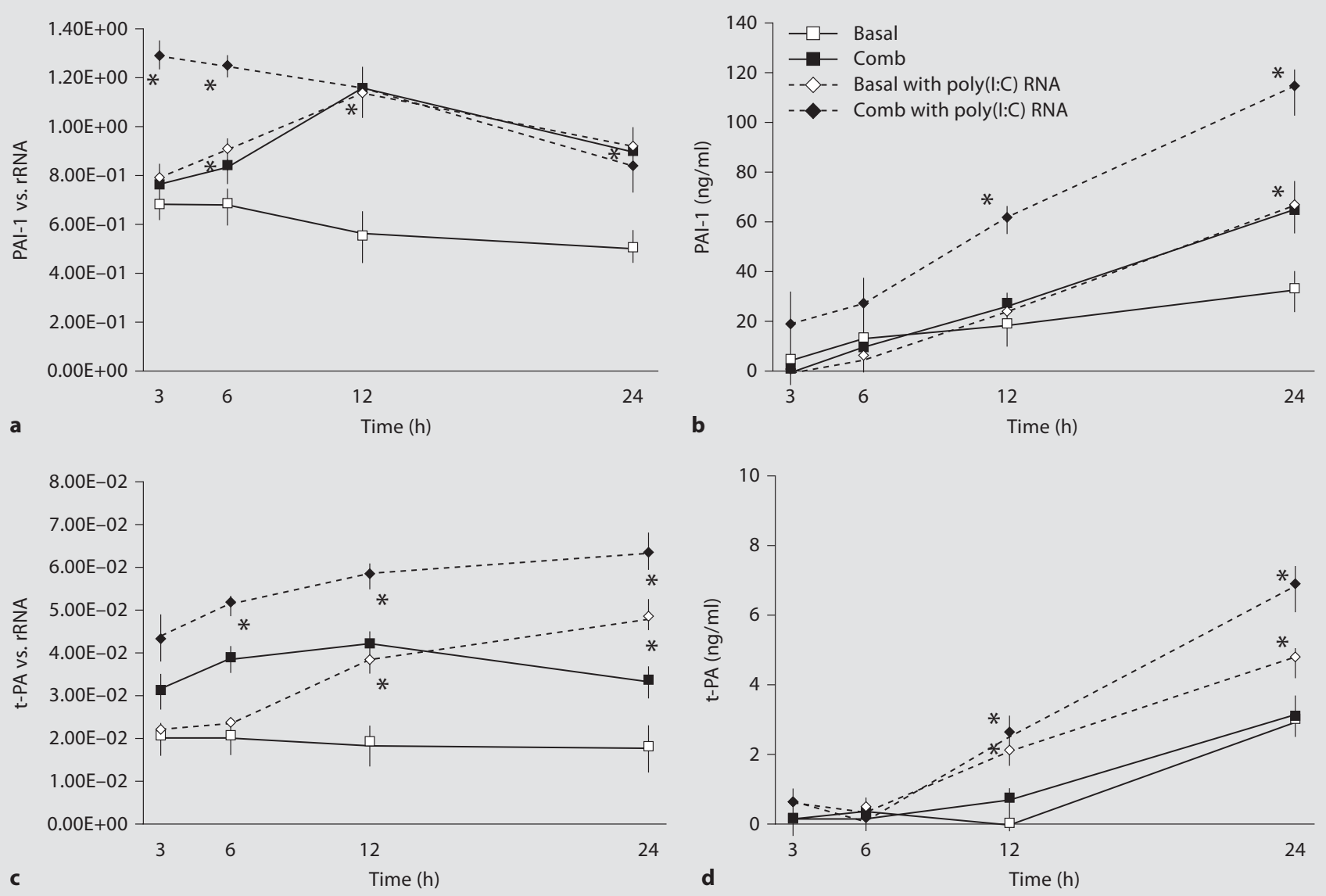

Fig. 3. Time-dependent influence of poly(I:C) RNA on synthesis of PAI-1 and t-PA. MC were pretreated under basal (Basal: open symbols) or cytokine combination conditions (Comb: filled symbols) as described in Methods and after washing they were incubated with (diamonds, discontinued line) or without (squares, continuous line) poly(I:C) RNA $(5 \mu \mathrm{g} / \mathrm{ml})$ for different time intervals $(3,6,12$ or $24 \mathrm{~h})$. The expressions of PAI-1 and t-PA were determined by real-time RT-PCR $(\mathbf{a}, \mathbf{c})$ and ELISA $(\mathbf{b}, \mathbf{d})$. Incubation of MC with poly(I:C) RNA increased PAI-1 mRNA expression when MC were cultivated under standard conditions and stimulated with poly(I:C) RNA with a maximum increase at $12 \mathrm{~h}$. When cells were pretreated with proinflammatory cytokines and incubated with poly(I:C) RNA, an early increase of PAI-1 synthesis was observed at 3 and $6 \mathrm{~h}$. Increase was significant at 12 and $24 \mathrm{~h} \mathrm{com-}$ pared to untreated cells, but no difference was seen compared to cytokine stimulated cells without poly(I:C) RNA incubation. PAI-

1 release measured by ELISA showed no significant difference after 3 and 6 h poly(I:C) RNA stimulation. After $12 \mathrm{~h}$, PAI- 1 release increased significantly when cells were stimulated with poly(I:C) RNA and pretreated with the combination of proinflammatory cytokines. After 24 h, PAI-1 synthesis was significantly increased when the cells were stimulated with poly(I:C) RNA under basal conditions, an effect which was further enhanced when cells were additionally pretreated with the cytokine combination. Poly(I:C) RNA stimulation results in a time-dependent increase of t-PA synthesis with a maximum at $24 \mathrm{~h}$, an effect enhanced by pretreatment with the cytokine combination. Values are means \pm SEM of three independently performed series of experiments. rRNA served as the reference gene. Significant differences are indicated for $\mathrm{p}$ values $<0.05\left(^{*}\right)$. Poly(I:C) RNA-stimulated conditions were compared with unstimulated conditions, both with and without additional cytokine pretreatment, respectively.

Glomerulonephritides are characterized by inflammatory processes leading to the release of a variety of proinflammatory cytokines and growth factors. Progression to renal failure in glomerular disease is mainly attributed to the development of glomerulosclerosis and interstitial

fibrosis. The turnover of ECM components is a tightly controlled process with the plasminogen-plasmin system playing a major role in the dissolution of fibrin and the degradation of ECM proteins by activation of MMPs [2]. As a matter of fact, an increased PAI-1 expression was 


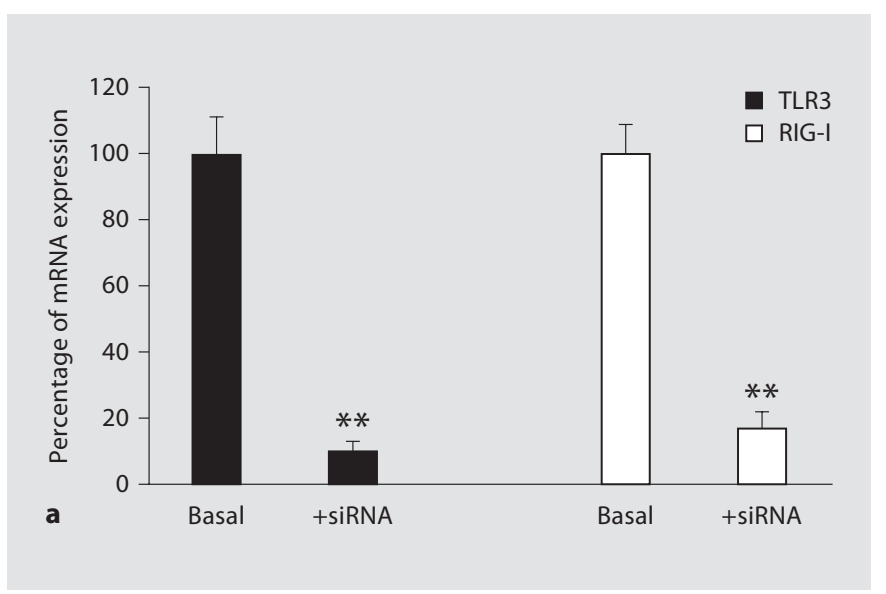

Fig. 4. Effects of transfection with siRNA for TLR3 and RIG-I on poly(I:C) RNA-induced expression of PAI-1 and t-PA. To test the effectivity of siRNA on basal gene suppression (a), expression of TLR3 and RIG-I was analyzed with (+ siRNA) and without (Basal) a 24-hour transfection with the specific siRNAs by real-time RT-PCR. siRNA specific for TLR3 and RIG-I suppressed the basal expression of the respective genes significantly. MC were stimulated with poly(I:C) RNA (5 $\mu \mathrm{g} / \mathrm{ml})$ for $24 \mathrm{~h}$. siRNA specific for TLR3 clearly reduced poly(I:C) RNA-induced mRNA expression of PAI-1 (b) and t-PA (c). siRNA specific for RIG-I had no effect on poly(I:C) RNA-induced expression of PAI-1 and t-PA. Values are means \pm SEM of three independently performed series of experiments. rRNA served as the reference gene. Significant differences are indicated for p values $<0.05\left(^{*}\right)$ or $0.01\left(^{* *}\right)$, respectively.

found in several forms of glomerulonephritis [9]. Glomerular PAI-1 can originate from infiltrating inflammatory cells or resident mesangial and endothelial cells. A common mechanism is supposed to regulate PAI-1 in all these cells, as previously supposed in murine models of lupus nephritis [28].

During the course of virally induced glomerulonephritides, immune complexes as well as free viral RNA reach the mesangium $[12,13]$. In adult healthy kidneys the viral receptor TLR3 is expressed on MC and is supposed to be important for the clearance of viral RNA. We have previously shown a role for TLR3 in HCV-associated glomerulonephritis [23]. Furthermore, activation of viral receptors as experimentally exemplified by stimulation with poly(I:C) RNA is supposed to be involved in the induction of various forms of glomerulonephritis as even lupus nephritis is found to worsen in MRL-Fas(lpr) mice injected with poly(I:C) RNA [29]. MC in cell culture have low TLR3 mRNA levels with a predominant intracellular protein localization. TLR3 expression is increased by
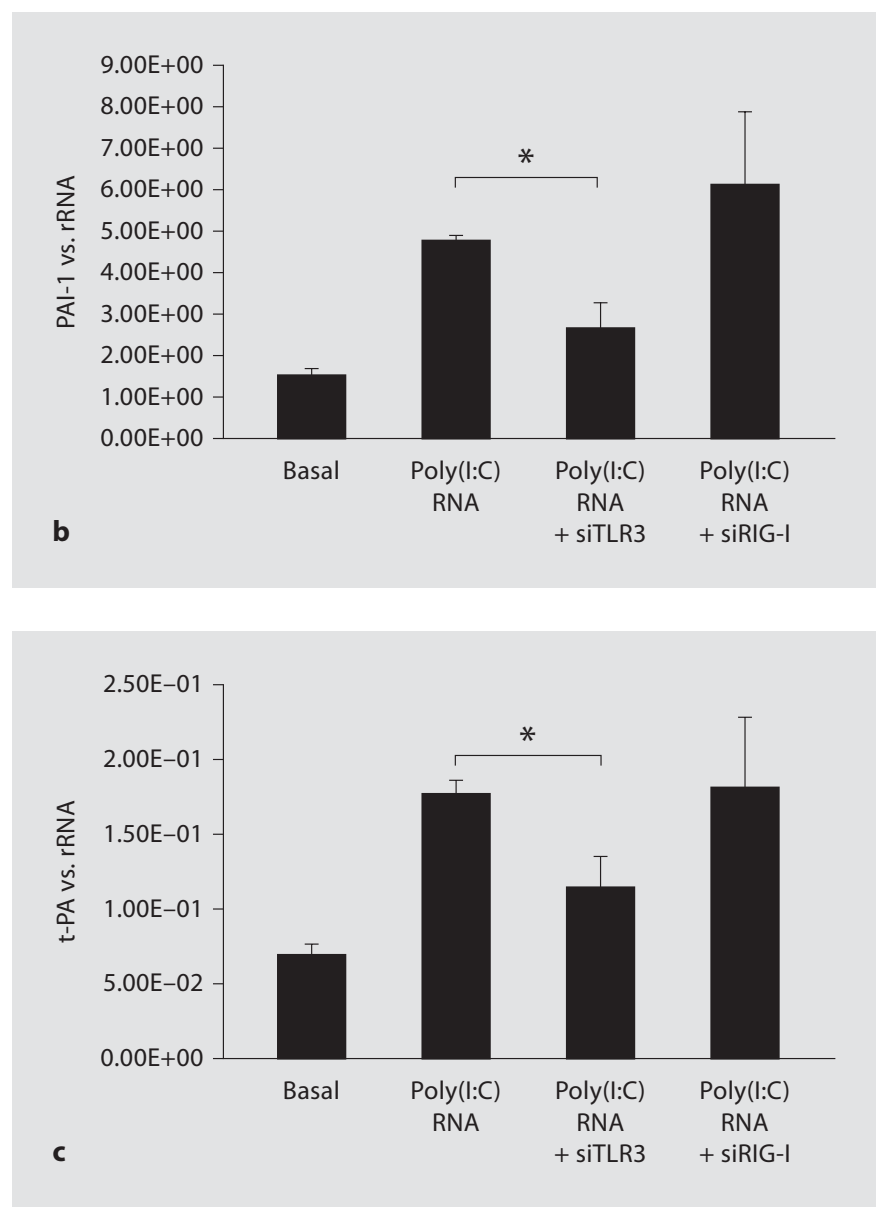

TNF- $\alpha$, IL-1 $\beta$, IFN- $\gamma$, the combination of these cytokines and the TLR3 ligand poly(I:C) RNA. Viral dsRNA has been recognized as a major ligand for TLR3 in many cell types including dendritic cells and non-immune cells such as MC $[23,30]$. It has been recently shown that also single-stranded RNA can act as a ligand for TLR3. Poly(I:C) RNA is a synthetic analogue for viral RNA and activates TLR3 [31]. In addition to TLR3, a role for the helicase RIG-I in viral infections was shown for several cell types $[21,26]$.

In our study, human immortalized MC express PAI-1 under basal culture conditions. PAI-1 expression was induced by treatment with poly(I:C) RNA, by stimulation with TNF- $\alpha$ and IL-1 $\beta$ alone and by combined stimulation with the proinflammatory cytokines TNF- $\alpha$, IL- $1 \beta$ and IFN- $\gamma$. The induction of PAI-1 by poly(I:C) RNA treatment was time- and dose-dependent and was enhanced after 3 and $6 \mathrm{~h}$ of poly(I:C) stimulation by pretreatment of MC with cytokines. This might be explained by an immediate upregulation of TLR3 by cy tokine stim- 
ulation [23] or a facilitated signal transduction. In contrast, the expression of t-PA in MC was not significantly affected by stimulation with any of the cytokines either individually or in combination, but was increased significantly by poly(I:C) RNA, especially in cytokine pretreated cells. Data from ELISA substantiate a corresponding increase in PAI-1 and t-PA protein synthesis with a delay of 6-12 h. Knockdown experiments with TLR3specific siRNA confirm the specificity of TLR3 activation and signal transduction in PAI-1 regulation as the poly(I:C) RNA-mediated increase in expression of PAI-1 and t-PA was inhibited by siRNA specific for TLR3 but not for RIG-I.

It therefore has to be supposed that the stimulation of viral receptors as TLR3 in the glomerular mesangium leads to an upregulation of both PAI-1 and t-PA, with the PAI-1 increase being earlier and more pronounced, especially under inflammatory conditions. This might result in an imbalance in plasmin activation and a reduced dissolution of fibrin and turnover of ECM proteins with generation of glomerular fibrosis. The observation that activation of TLR3 increases expression of both PAI-1 and t-PA is consistent with in vitro findings in several forms of glomerulonephritis [32]; it can be explained by the fact that physiologically both profibrotic and profibrinolytic components are necessary for regeneration and healing in glomerular inflammatory processes. The development of matrix abnormalities might not be specific for virally induced glomerular injury but is sup- posed to be characteristic for any form of immune-mediated glomerular disease. The functional role of mesangial viral receptors in the regulation of mesangial ECM is supported by our previous finding of an upregulation of MMP 9 in MC after activation of TLR3; the expression of MMP 2 and the MMP inhibitor TIMP-1 was not affected and RIG-I did not influence MMP expression [24]. Our results were obtained from an immortalized human mesangial cell line and similar experiments will therefore need to be undertaken using primary human MC in the future to determine whether they exhibit similar responses.

In summary, our results demonstrate how activation of viral receptors by dsRNA influences the mesangial synthesis of PAI-1 and t-PA. These results suggest that viral RNA could also influence the process of generation and degradation of ECM in the mesangium during immune-mediated glomerulonephritis by affecting mesangial PAI-1 and t-PA synthesis. We consider this to be a novel and attractive hypothesis for the development of glomerulosclerosis in virally induced glomerulonephritides.

\section{Acknowledgements}

This work was supported by a grant from the Deutsche Nierenstiftung to M.W. and a grant from the Wilhelm-Vaillant-Stiftung to M.W.

\section{References}

1 Baricos WH, Cortez SL, el-Dahr SS, et al: ECM degradation by cultured human mesangial cells is mediated by a PA/plasmin/ MMP-2 cascade. Kidney Int 1995;47:c1039_ c1047.

2 Vassalli JD, Sappino AP, Belin D: The plasminogen activator/plasmin system. J Clin Invest 1991;88:c1067-c1072.

3 Kincaid-Smith P: Coagulation and renal disease. Kidney Int 1972;2:c183-c190.

4 Nield GH, Cameron JS: Primary glomerulonephritis; in Remuzzi G, Rossi EC (eds): Haemostasis and the Kidney. London, Butterworth, 1989, pp 56-64.

5 Nath KA: Tubulointerstitial changes as a major determinant in the progression of renal damage. Am J Kidney Dis 1992;20:c1-c17

6 Floege J, Gröne HJ: Progression of renal failure: what is the role of cytokines? Nephrol Dial Transplant 1995;10:c1575-c1586.
7 Klahr S, Schreiner G, Ichikawa I: The progression of renal disease. N Engl J Med 1988; 318:c1657-c1666.

8 Grandaliano G, Gesualdo L, Ranieri E, et al: Tissue factor, plasminogen activator inhibitor-1, and thrombin receptor expression in human crescentic glomerulonephritis. Am J Kidney Dis 2000;35:c726-c738.

9 Hamano K, Iwano M, Akai Y, et al: Expression of glomerular plasminogen activator inhibitor type 1 in glomerulonephritis. Am J Kidney Dis 2002;39:c695-c705.

10 Purkerson ML, Joist JH, Greenberg JM, et al: Inhibition by anticoagulant drugs of the progressive hypertension and uremia associated with renal infarction in rats. Thromb Res 1982;26:c227-c240
11 Rondeau E, Mougenot B, Lacave R, et al: Plasminogen activator inhibitor 1 in renal fibrin deposits of human nephropathies. Clin Nephrol 1990;33:c55-c60.

12 Agnello V, Chung RT, Kaplan LM: A role for hepatitis $\mathrm{C}$ virus infection in type II cryoglobulinemia. N Engl J Med 1992,327:c1490c1495.

13 Meyers CM, Seef LB, Stehman-Breen CO, Hoofnagle JH: Hepatitis $\mathrm{C}$ and renal disease: an update. Am J Kidney Dis 2003,42:c631c657.

14 Klotman PE: HIV-associated nephropathy. Kidney Int 1999,56:c1161-c1176.

15 D'Amico G: The commonest glomerulonephritis in the world: IgA nephropathy. Q J Med 1987;64:c709-c727.

16 Akira S, Takeda K, Kaisho T: Toll-like receptors: critical proteins linking innate and acquired immunity. Nat Immunol 2001;2: c675-c680. 
17 Anders HJ, Banas B, Schlöndorff D: Signaling danger: toll-like receptors and their potential roles in kidney disease. J Am Soc Nephrol 2004; 15:c854-c867.

18 Alexopoulou L, Holt AC, Medzhitov R, Flavell RA: Recognition of double-stranded RNA and activation of NF- $\kappa$ B by toll-like receptor 3. Nature 2001;413:c732-c738.

19 Matsumoto M, Kikkawa S, Kohase M, et al: Establishment of a monoclonal antibody against human toll-like receptor 3 that blocks double-stranded RNA-mediated signaling. Biochem Biophys Res Commun 2002;293: c1364-c1369.

20 Cario E, Podolsky DK: Differential alteration in intestinal epithelial cell expression of toll-like receptor 3 (TLR3) and TLR4 in inflammatory bowel disease. Infect Immun 2000;68:c7010-c7017.

21 Vitour D, Meurs EF: Regulation of interferon production by RIG-I and LGP2: a lesson in self-control. Sci STKE 2007;384:c20.
22 Uchiyama-Tanaka Y, Mori Y, Kishimoto N, et al: Membranous glomerulonephritis associated with hepatitis $\mathrm{C}$ virus infection: case report and literature review. Clin Nephrol 2004;61:c144-c150.

23 Wörnle M, Schmid H, Banas B, et al: Novel role of toll-like receptor 3 in hepatitis C-associated glomerulonephritis. Am J Pathol 2006; 168:c370-c385.

24 Wörnle M, Roeder M, Sauter M, Ribeiro A Role of matrix metalloproteinases in viralassociated glomerulonephritis. Nephrol Dial Transplant 2009;24:1113-1121.

25 Banas B, Luckow B, Moller M, et al: Chemokine and chemokine receptor expression in a novel human mesangial cell line. J Am Soc Nephrol 1999,10:c2314-c2322.

26 Porubsky S, Schmid H, Bonrouhi M, et al: Influence of native and hypochlorite-modified low-density lipoprotein on gene expression in human proximal tubular epithelium. Am J Pathol 2004,164:c2175-c2187.

27 Matsukura S, Kokubu F, Kurokawa M, et al: Role of RIG-I, MDA-5, and PKR on the expression of inflammatory chemokines induced by synthetic dsRNA in airway epithelial cells. Int Arch Allergy Immunol 2007; 143(suppl 1):c80-c83.
28 Keeton M, Ahn C, Eguchi Y, et al: Expression of type I plasminogen activator inhibitor in renal tissue in murine lupus nephritis. Kidney Int 1995;47:c148-c157.

29 Patole P, Gröne HJ, Segerer S, et al: Viral double-stranded RNA aggravates lupus nephritis through toll-like receptor 3 on glomerular mesangial cells and antigen-presenting cells. J Am Soc Nephrol 2005;16:c1326-c1338.

30 Matsumoto M, Funami K, Tanabe M, et al: Subcellular localization of toll-like receptor 3 in human dendritic cells. J Immunol 2003; 171:c3154-c3162.

31 Marshall-Clarke S, Downes JE, Haga IR, et al: Polyinosinic acid is a ligand for toll-like receptor 3. J Biol Chem 2007;282:c24759c24766.

32 Aya N, Yoshioka K, Murakami K, et al: Tissue-type plasminogen activator and its inhibitor in human glomerulonephritis. J Pathol 1992;166:c289-c295. 